\title{
On Conceptual Potentials of Metonymy
}

\author{
Hans-Harry Drößiger \\ The Kaunas Faculty of Humanties, Vilnius University, Vilnius, Lithuania \\ Email: hdroessi@gmail.com
}

How to cite this paper: Drößiger, H.-H. (2016) On Conceptual Potentials of Metonymy. Open Access Library Journal, 3: e3178. http://dx.doi.org/10.4236/oalib.1103178

Received: October 27, 2016

Accepted: November 11, 2016

Published: November 14, 2016

Copyright $\odot 2016$ by author and Open Access Library Inc.

This work is licensed under the Creative Commons Attribution International License (CC BY 4.0).

http://creativecommons.org/licenses/by/4.0/

(c) (i) Open Access

\begin{abstract}
Metonymy is a more deeply embedded and ingrained capability of the human mind than classical approaches may tell. The cognitive turn in linguistics changed the point of view to the interaction between language and mind, thus, new approaches to understand what metonymy is might come into life. The takeover of ideas of metonymy into applied branches of linguistics like translation studies (as a complement to the idea of equivalence), into researches of language comparison (intracultural-intercultural, diachronic-synchronic), or into the philosophy of science (on sorts and forms of definition of terms) may reveal the true nature and the potentials of metonymy. This leads to a comprehension of metonymy as a common, probably universal capability of human language and thinking-beyond the boundaries of languages and cultures.
\end{abstract}

\section{Subject Areas}

Linguistics, Literature

\section{Keywords}

Metonymy, Contiguity, Cognitive Linguistics, Translation Studies, Etymology

\section{Introduction}

In the majority of linguistic scholarly papers, two approaches to metonymy dominate. They ground in a long linguistic and partially also in a long philosophical tradition. Therefore, we may say that these two classical approaches are a part of the common linguistic knowledge. In the first one, the classical-philological approach, metonymy is a subject to traditional linguistic branches like stylistics, lexicology, and semantics. This approach is situated on lexical-denotative level and is explained as transfer of significant. To this older approach, metonymy is as conceptual metonymy and metonymical conceptualization within the framework of cognitive linguistics in opposition. The cog- 
nitive linguistic approach has been widely spread since the 1980ies und evoked profound discussions, in which metonymy is understood as a linguistic and cognitive competence-interpreted as a means of acquisition, processing and usage of knowledge (learning, consciousness, knowledge transfer), as pointed out in Drößiger [1]. Based on this cognitive linguistic approach, some more areas of application and explanation, possibly not only in linguistics, are conceivable.

\section{Metonymy as a Scientific and Epistemological Concept}

According to this approach, it is possible to state that only in bringing several definitions and descriptions of scientific terms together the principle of conceptual metonymy for scientific work might be realized. A precondition to this is that definitions and descriptions of scientific terms should not be seen as competing components but as complementary ones within a space of contiguity concerning theories. This is because of the assumption that complementary components of that space of contiguity represent definitions and descriptions of scientific terms from distinguishable perspectives. The effect of this assumption would be not only a more complete picture how to understand scientific terms, but also a higher explanatory force for theoretical conceptions.

Specialized literature in translatology shall be used to illustrate the explanatory force of conceptual metonymy, exemplified by one of the basic topics in translatology, the ways and forms of "linguistic encounters of cultures". The descriptions or notions of these encounters are not only worked out in several directions and schools of translatology, but they also use different linguistic expressions to emphasize certain communicative and cognitive aspects of these "linguistic encounters of cultures". To make it clear, it is not my intention to improperly merge or mix various theoretical positions. My point is to show how the process of "linguistic encounters of cultures" might be seen and comprehended so differently. I call this communicative and cognitive diversity of the "linguistic encounters of cultures" the T.R.A.M.I.S. phenomenon. In the following paragraphs, the corresponding expressions to that phenomenon are highlighted in bold letters, including also the quotes:

“T” stands for translation (in the very well known sense), but also for "transplantation". Mohanty speaks of transplantation of that what belongs to a culture into another culture: "I earnestly believe that such a transplantation is possible provided that the translator treats translation not as an exercise but as a mediation in which not only two languages but also two cultures support each other." [2] — “T" stands also for "transpose" as it was used by Vinay/Darbelnet [3].

"R" is used by D'hulst and stands for "rendering cultural items" [4]. That usage of the term rendering seems to be an alternative for translation, yet, in that special case, D'hulst does not focus on equivalence between codified lexical items of two or more languages but on a way to express the original meaning by any appropriate linguistic units of a target language.

" $\mathrm{A}$ " refers to the most frequently occurring aspects, which also present the largest va- 
riety of that "linguistic encounters of cultures". There is the "assimilation" in Grosman: "In its basic, initial stage, cross-cultural assimilation is but a form of the usual reader assimilation of the text, resulting from an effort to make sense, to force the text into acceptability" [5]. This assimilation leads as Grosman puts it almost automatically to "acceptability", if not even to "acceptance" of a foreign culture.-Nord names it (like many others) "adaption”, thus, “... adaptions often are the only way to ensure that a translation 'works' in the target-culture situation it is produced for" [6].

"M" was already mentioned in the quote above from Mohanty [2] who used it for "mediation". D'hulst takes "mediation" in another sense, which is unlike Mohanty's position not so common because he puts "cultural translation" as "mediation between different cultural practices" [4]. Furthermore, "M" is used for "mirror", whereby the "linguistic encounters of cultures" gets a new emphasis. This is because Vinay \& Darbelnet say looking at only one language and culture community that "languages mirror culture" [3]. Considering this, we may suppose that one language is able to "mirror" more cultures than the own.

"I" is used by Toury and stands for "introducing". He says about translation that “... translation is basically designed to fulfill ... the needs of the culture which would eventually host it. It does so by introducing into that culture a version of something which has already been in existence in another culture, making use of a different language, which-for one reason or another-is deemed worthy of introduction into it" [7]. Moreover, Toury uses "I also for "incorporate": "The introduced entity itself, the way it is incorporated into the recipient culture, is never completely new, never alien to that culture on all possible accords" [7]. In this quote, he does not directly name the commons between cultures, but his outlines could be interpreted in such a way. It is about a basic statement that it is very necessary to emphasize what cultures have in common instead of focusing on that what divides them.

And finally "S", because Mohanty writes that “... through his act of translation, the translator generates a symbiosis between the source and the target culture" [2]. But Mohanty uses " $\mathrm{S}$ " also for “... a mediation in which not only two languages but also two cultures support each other" [2].

This synopsis presents different points of view including their different practical and methodical consequences about that whether and how the encounter of two language and culture communities may happen. The spectrum of opinions ranges from a symbiosis of two cultures as in Mohanty [2] to the rejection of the foreign as in Toury [7]. To avoid any misunderstandings, it is necessary to say that Toury sees himself not as a representative or follower of such a radical position of rejecting the foreign. He discussed a sort of scaling: "Rather, the novelty of an entity derives from the target culture itself, and relates to what that culture is willing (or allowed) to accept vs. what it feels obliged to submit to modification, or even totally reject" [7].

Yet, the majority of descriptions comprehends the "linguistic encounters of cultures" more or less as mediation to fulfill or satisfy the needs of a certain culture, as D'hulst [4] puts it. Cabré also speaks about communicative needs but first of all within the area 
of specialized linguistic communication. But it can be seen easily that the handling with communicative needs closely correlates with the cognitive needs, or-as I call it-a certain knowledge should be and has to be made cognitively and communicatively available in a target language and culture: "Their [d. i. experts-author] communicative needs start from the knowledge of the concept and from the need to communicate it; their interest in terminology focuses on concepts and how they can be named clearly and unambiguously" [8].

\section{Metonymy as a Translational Concept}

This approach might be described as metonymical movements within the mental space of contiguity. The linguistic expression of these movements are used to render lexical units into a target language, because these linguistic and cognitive movements allow to find or to create metonymically coined correspondences, which are alternatives to codified equivalents. Partially, these correspondences are even more expressive than the regular equivalents or sometimes better fit to the sorts of text where they had to occur. My analysis of the renderings of culture-bound words in the translations of the Brothers' Grimm Fairytales (GFT) show that three main types of metonymical movements might be distinguished [9].

Within the framework of translation studies, the key point for metonymy is the theoretical conception of equivalence whose linguistic manifestations as equivalents on lexical-denotative level are of interest. Yet, the term "equivalent" should be used exclusively for such lexical units that are codified, meaning that they completely appropriate one to each other. From that, other occurrences have to be distinguished, as they are occasionally (i.e. not codified) rendered words from a source language, which depend on certain discourse areas, sorts of text, speaker's intentions and text style. These not codified renderings into a target language might be taken as deviations from the usual lexical-denotative equivalence. Linguistically, these deviations are formed by using standard vocabulary but in a way that the created word for the needs of the target language is not an equivalent in a literal sense. To avoid an improper terminological blending, these units characterized as deviations from the codified standard I will call "correspondences". As a term, "correspondence" claims the status of a hyperonym for all deviations from lexical-denotative equivalents. Due to the fact that in the translations of the GFT not always codified equivalents appear, it was possible to work out several techniques of rendering of culture-bound words. The majority of them can be taken as deviations in the above mentioned sense, but they all are expressions of metonymical movements in certain mental spaces of contiguity.

Metonymical correspondences are the result of linguistic and cognitive movements in the mental space of contiguity. Linguistically, they are expressed by lexical units. Three types of these movements can be distinguished. Illustrating examples for the instances of metonymical movements were taken from Drößiger [9]. Source language is German, target languge English. For a better understanding of the German words, a backtranslation is added. 
a) Metonymical SHIFT is a semantic and conceptual movement on a "vertical axis", in which the central point is taken by a basic category. This basic category might be identical with a hyperonym. The semantic and conceptual movements go upwards beyond the basic category, which I will call SHIFT UP, or in some cases downwards below the basic category, which I will call SHIFT DOWN. Examples for SHIFT UP are Kammer [chamber], Stube [parlor] > room; Brot [bread] > food; examples for SHIFT DOWN are Gefäß [container] > vase; Gebäude [building] > castle.

b) Metonymical TWIST operates on the idea of the mental space of contiguity where metonymical movements can take place. In such cases, the semantic relations inside of concepts are used to get alternative perspectives or interpretations of these concepts. Typical occurrences of TWISTs are the change from event to activity: Jagd [hunt] > to go out hunting; from place to activity: Acker [field] > to go and plough; from instrument to activity: Axt [ax] > chopping down a tree, change of the sort: Knecht [servant] > kitchen boy, changes within the Whole-Part-relation: Essen [food] > meat, Stube [parlor] > door.

c) Metonymical DISTORTION is a movement inside the mental space of contiguity that goes beyond a SHIFT or TWIST. The result is an enormous semantic and conceptual distance to the meaning of the original word. The used word or designation in the target language can only be understood by considering aspects of abstraction and/or vagueness to see some sort of relation to the original concept. Examples are Diener [servants] > high officials, Kammer [chamber] > shed; Huhn [hen] > cock.

\section{Metonymy as an Ethnic-Cognitive Concept}

This approach will only work by doing a comparative analysis on lexical level, especially considering the basic vocabulary. Also, more complex speech acts and their intentions might be analyzed when the observation and description change from a pure lexical level to the syntactic and/or textual level.

This approach to metonymy shall be explained by using the example "tree" quoted from a book by the German psycholinguist Hoffmann: "A tree can, depending on what context of behavior it is put in, be classified as a protector against rain, as a viewpoint, as a hiding place, as an obstacle, as a gift, as a producer of oxygen, as an object of nature to be protected, as a nesting place, as a provider of shadow, as wood etc." (Original quote in German: "Ein Baum kann, je nachdem, in welchen Verhaltenskontext er gestellt ist, als Regenschutz, als Aussichtsmöglichkeit, als Versteck, als Hindernis, als Geschenk, als Sauerstoffproduzent, als zu schützendes Umweltobjekt, als Nistplatz, als Schattenspender, als Holz usw. klassifiziert werden.”) [10].

Despite the somewhat vague usage of the expression "context of behavior" (Germ. Verhaltenskontext), which can be interpreted as communicative situation, discourse domain or even more abstract as language and culture community, this listing shows that the distinguishable points of view to "tree" ground in various features of or on different experiences with that object, for example objective features like "size", "height", "volume", "leafy canopy", "silhouette"; positive evaluative features like "protector 
against rain" or "provider of shadow"; negative evaluative features like "obstacle". A tree might be all of this that Hoffmann points out, but certain communicative situations or discourse domains determine the features of a tree to be emphasized. If all these readings would be combined or merged within one concept, then a complex mental space of contiguity to tree is established. The word for tree in a single language refers to some but not to all conceptual aspects.

A look into the etymology of some Indo-European languages shows that different motives for the naming of "tree" (corresponding to single aspects of the mental space of contiguity of tree) are the reasons for the creation of the linguistic signs in each language:

The meaning of the German word Baum is originally "beam", "used for constructing", which phonetically corresponds to the English cognate beam. Yet, the codified English designation for "tree" is tree, which has the original meaning "tar used for constructing". In a similar way, cognates in other Germanic languages appear: Icelandic tré, Norwegian tre, Swedish träd. It is striking that the English tree has semantic and motivational cognates in Russian dereva, Bosnian drvo, Byelorussian dreva, Polish drzewo, and these cognates are phonetically similar to each other because they might have a common origin in the Slavic root * ${ }^{\prime} r$ ' $v$, originally meaning "tar". The Latin arbor and its historically subsequent French arbre, Italian albero, Catalan arbre, Spanish arbol are motivated-following the etymology of Latin-by the existence of leaves and branches as the botanical structure of a tree. Considering the fact that a tree essentially consists of wood, it can be said that this was the motive for designating it in Lithuanian medis, which is a polysemous word meaning also "wood". Finally, there is the Greek word dendron, which has its ancestor in the Indo-Aryan danda originally meaning "cudgel", "bough", thus the motive for designation is here also the botanic structure of a tree. The sources of the etymological information given here in a compiled form are [11] [12] [13].

This kind of observations may lead to the conclusion that at least within the Indo-European language family we may talk about an ethnic metonymy. In a most extreme case, each single language created its own designations representing a language and culture community's world view, which grounds in meaningful motives for these designations. But it seems that such extreme cases are not really conceivable as the little overview to "tree" may tell. However, it is important to see that beyond the usual language groups (Germanic, Slavic, Roman etc.) shared designation motives between languages can be stated. So, a thesis might be put forward that the European language and culture communities have more in common than usually assumed. Returning to the example presented by Hoffmann, it might be supposed that certain ethnic groups using other words for trees than the Europeans do, because of their traditions and history might have been considered aspects like "provider of shadow" or "protector against rain" as motives for naming "tree".

Thus, it can be stated that alongside the lexical-denotative equivalents, another sort of equivalents appears, which just in terms of methodology goes beyond a classical lex- 
ical-semantic and corpus-based analysis by requiring a different approach considering ways of studies in anthropology, cultural semiotics and Indo-European research. To keep continuity by using the term equivalent, the attribute ethnic should be used because the designations related to such instances are codified as common equivalents. So, ethnic equivalents allow to work out findings concerning commons and differences in the world view between nations and people.

As already hinted at the concept tree, the world view, the interpretation of the world, the environment and the existence but also the historical comprehension within a language and culture community play an essential role for the comparison of language and culture communities. Yet, the commons between these communities should outweigh the differences between them because of their possible political misinterpretation. Two sorts of ethnic correspondences might be distinguished: 1. Historically culturally and linguistically determined ethnic equivalents as for "tree" are expressing a diversity of world views in each language and culture community. A similarly revealing example is salt, as shown in [11], which has in almost all Indo-European languages the same word stem $(s) a l-$, although the word appears in some phonetically or sometimes morphologically coined variants. But there is one remarkable exception: Lithuanian. The Lithuanian word for "salt" is druska, and by [14] it means "trupinelis, gabaliukas" (crumbs, little particle) and "šukès; tai, kas suskaldyta, suardyta; maži gabaliukai" (fragments; something that was chopped up into pieces; little pieces). Thus, the Lithuanian word druska is in a noticeable contrast to salt originally meaning "mud-colored" [15]. Considering aspects of ethnic equivalence it seems to be obvious that in the Indo-European languages except Lithuanian, the original motive for the designation of "salt" was its color, while in Lithuanian, the motive to be named came possibly from the texture of the object salt. This allows conclusions to different world views of the several ethnic groups or language and culture communities. 2. Cultural-semiotic, ethnic equivalents are the second sort. For example, in traditional stylistics, the phenomenon named as allegory directs under the perspective of equivalence to culturally and semiotically varied designations, which are manifestations of an interpretation of the material and spiritual world view. An appropriate instance is Death as the name of an allegorically comprehended character. The cultural-semiotic variations, directing to cultural-semiotic equivalents, correlate with the assigning of a natural sex to that character: in German and English male, while in Lithuanian female-giltine [14]. This significant conceptual distinction causes consequences for creating and interpreting a text to be translated or for artistic portrayals.

\section{Conclusion}

Metonymy is a more deeply embedded and ingrained capability of the human mind than classical approaches may tell. The cognitive turn in linguistics changed the point of view to the interaction between language and mind, thus, new approaches to understand what metonymy is might come into life. As the outlines above have presented, new ideas concerning with the phenomenon of metonymy are worth to be considered. 
More investigations especially in the form of empirical research into large corpora are necessary to proof the suggested ideas about metonymy. If this will once lead to a better understanding of that what is called metonymy, then its existence in the shadow of metaphor might come to an end, because metonymy can tell more about the mechanisms between language and mind than metaphor would ever be able to.

\section{References}

[1] Drößiger, H.-H. (2007) Metaphorik und Metonymie im Deutschen. Untersuchungen zum Diskurspotenzial semantisch-kognitiver Räume (Metaphor and Metonymy in German. Investigations into the Discourse Potentials of Semantic-Cognitive Spaces). Dr. Kovač, Hamburg.

[2] Mohanty, N. (1994) Translation: A Symbiosis of Cultures. In: Dollerup, C. and Lindegaard, A., Eds., Teaching Translation and Interpreting 2. Insights, Aims, Visions. Papers from the Second Language International Conference Elsinore, Denmark, 4-6 June 1993, Benjamins, Amsterdam, Philadelphia, 25-37. https:/doi.org/10.1075/btl.5.06moh

[3] Vinay, J.-P. and Darbelnet, J. (1995) Comparative Stylistics of French and English. A Methodology for Translation. Benjamins, Amsterdam, Philadelphia.

https:/doi.org/10.1075/btl.11

[4] D’hulst, L. (2008) Cultural Translation. A Problematic Concept? In: Pym, A., Shlesinger, N. and Simeoni, D., Eds., Beyond Descriptive Translation Studies. Investigations in Homage to Gideon Toury, Benjamins, Amsterdam, Philadelphia, 221-232.

https:/doi.org/10.1075/btl.75.18dh

[5] Grosman, M. (1994) Cross-Cultural Awareness: Focusing on Otherness. In: Dollerup, C. and Lindegaard, A., Eds., Teaching Translation and Interpreting 2. Insights, Aims, Visions. Papers from the Second Language International Conference Elsinore, Denmark, 4-6 June 1993, Benjamins, Amsterdam, Philadelphia, 51-57. https:/doi.org/10.1075/btl.5.10gro

[6] Nord, C. (1994) Translation as a Process of Linguistic and Cultural Adaption. In: Dollerup, C. and Lindegaard, A., Eds., Teaching Translation and Interpreting 2. Insights, Aims, Visions. Papers from the Second Language International Conference Elsinore, Denmark, 4-6 June 1993, Benjamins, Amsterdam, Philadelphia, 59-67.

[7] Toury, G. (1995) Descriptive Translation Studies and Beyond. Benjamins, Amsterdam, Philadelphia. https:/doi.org/10.1075/btl.4

[8] Cabré, M.T. (1999) Terminology. Theory, Methods and Applications. Benjamins, Amsterdam, Philadelphia. https:/doi.org/10.1075/tlrp.1

[9] Drößiger, H.-H. (2015) Realienbezeichnungen in den Kinder- und Hausmärchen der Brüder Grimm. Intrakulturelle und interkulturelle Aspekte (Culture-Bound Words in the Brothers' Grimm Fairy Tales. Intracultural and Intercultural Aspects). Dr. Kovač, Hamburg.

[10] Hoffmann, J. (1986) Die Welt der Begriffe. Psychologische Untersuchungen zur Organisation des menschlichen Wissens (The World of Concepts. Psychological Investigations into the Organization of Human Knowledge). Deutscher Verlag der Wissenschaften, Berlin.

[11] Grimm, J. and Grimm, W. (1998-2004) Deutsches Wörterbuch (The German Dictionary). http://www.dwb.uni-trier.de/

[12] Frisk, H. (1960) Griechisches etymologisches Wörterbuch (Dictionary of Greek Etymology). Carl Winter, Heidelberg.

[13] Doederlein, L. (1841) Handbuch der lateinischen Etymologie (Handbook of Latin Etymology). Friedrich Christian Wilhelm Vogel, Leipzig. 
[14] Lietuvių kalbos etimologinio žodyno duomenų bazė (Data Base of Lithuanian Etymological Dictionary). http://etimologija.baltnexus.lt/?w=druska

[15] Duden. Das Herkunftswörterbuch (The Dictionary of Etymology) (2005) Bibliographisches Institut \& F. A. Brockhaus AG, Mannheim:. 3., völlig neu bearbeitete und erweiterte Auflage (Third, Completely Newly Revised and Extended Edition).

Submit or recommend next manuscript to OALib Journal and we will provide best service for you:

- Publication frequency: Monthly

- 9 subject areas of science, technology and medicine

- Fair and rigorous peer-review system

- Fast publication process

- Article promotion in various social networking sites (LinkedIn, Facebook, Twitter, etc.)

- Maximum dissemination of your research work

Submit Your Paper Online: Click Here to Submit

Or Contact service@oalib.com 